\title{
Neuroticism-related personality traits are associated with posttraumatic stress after abortion: findings from a Swedish multi- center cohort study
}

Inger Wallin Lundell ${ }^{1,2^{*}}$ (D) Inger Sundström Poromaa ${ }^{1}$, Lisa Ekselius ${ }^{3}$, Susanne Georgsson ${ }^{2,4}$, Örjan Frans ${ }^{5}$, Lotti Helström ${ }^{6}$, Ulf Högberg ${ }^{1}$ and Agneta Skoog Svanberg ${ }^{1}$

\begin{abstract}
Background: Most women who choose to terminate a pregnancy cope well following an abortion, although some women experience severe psychological distress. The general interpretation in the field is that the most consistent predictor of mental disorders after induced abortion is the mental health issues that women present with prior to the abortion. We have previously demonstrated that few women develop posttraumatic stress disorder (PTSD) or posttraumatic stress symptoms (PTSS) after induced abortion. Neuroticism is one predictor of importance for PTSD, and may thus be relevant as a risk factor for the development of PTSD or PTSS after abortion. We therefore compared Neuroticism-related personality trait scores of women who developed PTSD or PTSS after abortion to those of women with no evidence of PTSD or PTSS before or after the abortion.

Methods: A Swedish multi-center cohort study including six Obstetrics and Gynecology Departments, where 1294 abortion-seeking women were included. The Screen Questionnaire-Posttraumatic Stress Disorder (SQ-PTSD) was used to evaluate PTSD and PTSS. Measurements were made at the first visit and at three and six month after the abortion. The Swedish universities Scales of Personality (SSP) was used for assessment of Neuroticism-related personality traits. Multiple logistic regression analyses were performed to investigate the risk factors for development of PTSD or PTSS post abortion.

Results: Women who developed PTSD or PTSS after the abortion had higher scores than the comparison group on several of the personality traits associated with Neuroticism, specifically Somatic Trait Anxiety, Psychic Trait Anxiety, Stress Susceptibility and Embitterment. Women who reported high, or very high, scores on Neuroticism had adjusted odds ratios for PTSD/PTSS development of 2.6 (Cl 95\% 1.2-5.6) and 2.9 (Cl 95\% 1.3-6.6), respectively.

Conclusion: High scores on Neuroticism-related personality traits influence the risk of PTSD or PTSS post abortion. This finding supports the argument that the most consistent predictor of mental disorders after abortion is pre-existing mental health status.
\end{abstract}

Keywords: Abortion induced, Anxiety disorders, Personality, Stress disorder, post-traumatic

\footnotetext{
* Correspondence: inger.wallin.lundell@liu.se

'Department of Women's and Children's Health, Uppsala University, -751 85 Uppsala, SE, Sweden

${ }^{2}$ Sophiahemmet University, Box 5605, - 11486 Stockholm, SE, Sweden

Full list of author information is available at the end of the article
} 


\section{Background}

An unwanted pregnancy is a concern for every affected woman. Most women who choose to terminate a pregnancy cope well and report positive feelings such as relief and release after the abortion [1, 2]. Although some women experience severe psychological distress following an abortion [3], the general interpretation in the field is that the most consistent predictor of mental disorders post abortion is the mental health issues that women present with prior to the abortion [3, 4]. However, the concern that induced abortion may cause mental health problems is often raised in the public debate [3], and although heavily criticized for methodological flaws, some researchers continue to advocate that induced abortion is associated with an increased risk for mental health problems $[5,6]$.

From the present study, we have previously reported that few women develop PTSD or posttraumatic stress symptoms (PTSS) after induced abortion. Risk factors for PTSD or PTSS post abortion in our cohort were young age, low educational level, nulliparity, and need for counseling before abortion [7]. In other settings, PTSD risk factors also include female sex [8-10], and type of trauma, with sexual trauma being associated with the highest risk for PTSD, followed by exposure to crime and witnessing violence [10-14]. Furthermore, preexisting mental disorders, alcohol dependence, and problem-focused coping strategies are other factors associated with the risk of PTSD [13].

One factor that might help explain why some, but not all, traumatized people develop PTSD is the individual differences in personality traits, and predominantly the Neuroticism-related traits. Neuroticism is a stable personality trait which encompasses the tendency for a person to experience the world as threatening and distressing. Individuals with high scores on Neuroticism are typically anxious and vulnerable to stress, lack selfconfidence, and are easily frustrated [15]. The trait is associated with increased risk for development of psychiatric disorders and the association between Neuroticism and depressive and anxiety disorders is well known [16-21]. Although Neuroticism and stressful life events are independent predictors of mood and anxiety disorders, they also interact such that individuals with high Neuroticism tend to experience major life events as more stressful than others do [22]. Neuroticism-related personality traits is reported to predict the PTSD response to trauma [23] and may be associated with the development of PTSD [22-25].

On the basis of previous research suggesting that Neuroticism is an important predictor for PTSD [13, 22, 23], we aimed to investigate whether high scores of Neuroticism-related personality traits is a risk factor for development of PTSD or PTSS post abortion. The study was conducted in Sweden where the abortion context differs from many other countries. According to the Swedish Abortion Act of 1974, women are guaranteed a free abortion up to the 18th gestational week. Induced abortions are only performed by physicians or specially trained nurse- midwives in public hospitals or in private clinics that have been approved by the Swedish National Board of Health and Welfare [26]. Approximately 37,000 women undergo an induced abortion every year [27]. Up to gestational week nine, women can choose the abortion method, either medical or surgical, in consultation with the gynecologist or the midwife. Women need not declare their reason for the abortion [26]. Surgical abortion is decreasing among first trimester abortions in favor of medical abortions, and today, the majority of the medical abortion before gestational week nine are performed at home [27]. If needed, women seeking abortion are also offered consultation with a social worker [26]. During the study period $79 \%$ of all abortions were performed before gestational week nine and of those $87.5 \%$ were medical abortions [28].

Thus, the primary aim in this multi-center cohort study was to compare Neuroticism-related personality trait scores of women who developed PTSD or PTSS post abortion with those of women with no posttraumatic stress prior to or after a first trimester abortion. A secondary aim was to explore the influence of violence and sexual trauma exposure for the development of PTSD or PTSS post abortion.

\section{Methods}

This study is part of a multi-center cohort study targeting women who requested an induced abortion between September 2009 and June 2010 at the outpatient clinics of the Obstetrics and Gynecology Departments of six public hospitals in Sweden. Previous publications from the data set have addressed the prevalence of PTSD and PTSS post abortion, and the sociodemographic and clinical risk factors for PTSD or PTSS development [7, 29, 30]. All women who requested an induced abortion before the end of gestational week 12 were approached for participation, and the only exclusion criterion for the study was the inability to read and understand Swedish [29]. Women were informed about the study during their registration for the first abortion visit. Women who agreed to participate received written information about the study, together with a questionnaire (baseline assessment). They signed an informed consent and completed the first questionnaire at the clinic. Overall, 2602 women were invited, and 1514 women consented to participate. Two follow-up questionnaires were sent by post to the participating women, one at 3 months and another at 6 months after the abortion [7]. 
The baseline questionnaire solicited information on sociodemographic variables such as age, marital status, education, ethnicity, and tobacco and alcohol use. Supplementary information was retrieved from medical records and included parity, number of previous abortions, abortion method, place of abortion (home or at the clinic), antidepressant use, and psychosocial support during the abortion process.

\section{Measurements}

The Screen Questionnaire-Posttraumatic Stress Disorder (SQ-PTSD) [11] was used for a self-reported diagnosis of PTSD and of PTSS at baseline, and at the 3- and 6month assessments. The instrument is based on the Diagnostic and Statistical Manual of Mental Disorders, Fourth Edition (DSM-IV) diagnostic criteria for PTSD [31], and assesses trauma experiences as well as trauma symptoms [11]. The DSM-IV criteria are: A1) confrontation with the stressor involves actual or threatened death or serious injury, or a threat to the physical integrity of self or others; A2) responses of fear, helplessness, or horror to the confrontation; B) persistent re-experiencing of the traumatic event in intrusive thoughts, nightmares, or flashbacks; C) persistent avoidance of stimuli associated with the event and emotional numbing symptoms, described as an inability to experience any positive feelings such as love, contentment, satisfaction, and happiness; D) hyperarousal symptoms such as difficulties sleeping, concentrating, and controlling anger; E) duration of the disturbance (symptoms of criteria B, C, and D) for more than 1 month; F) disturbance causes clinically significant distress or impairment in social, occupational or other important areas of functioning [31].

In addition, exposure to violence was assessed by two questions i) Have you ever been beaten or attacked? ii) Have you ever been threatened with beating or attack? A positive response to at least one of these two questions was considered as being exposed to violence. Sexual trauma was assessed by two questions i) Have you ever been violently forced to perform sexual acts? ii) Have you ever been threatened into performing sexual acts? A positive response to at least one of these two questions was considered as being exposed to sexual trauma.

Only women who met all the DSM-IV criteria from $\mathrm{A}$ to $\mathrm{F}$ were classified as having a research diagnosis of lifetime PTSD. In previous studies different terms have been used to denote individuals who only partly meet the diagnostic criteria: sub-threshold PTSD, partial PTSD, or PTSS [32]. In the present study, the term PTSS was used, which was defined as prevalence of $\mathrm{A} 1$ and $\mathrm{A} 2$ criteria together with one or more of the re-experiencing, avoidance, or hyperarousal symptoms (B-C-D criteria).
The Swedish universities Scales of Personality (SSP) [33] instrument was used for evaluation of personality traits at the baseline assessment. SSP is a self-rating questionnaire designed to measure personality traits associated with vulnerability for psychopathology. The inventory is a revised version of the Karolinska Scales of Personality (KSP) [34]. The development of SSP improved the psychometric quality, and reduced the total number of items. Thus the SSP comprises 91 items divided into 13 scales, where previous factor analysis has yielded a three factor solution [33]. Factor 1 compromises personality scales assessing traits of Neuroticism; Somatic Trait Anxiety (tending to experience autonomic arousal; restlessness and tension); Psychic Trait Anxiety (worried, insecure, and anxious); Stress Susceptibility (easily stressed when hurried or facing new tasks); Lack of Assertiveness (non-assertive in social situations); Embitterment (dissatisfied, blaming, and envying others); Mistrust (suspicious, distrustful). Factor 2 includes scales assessing Aggressiveness; Social Desirability (socially conforming, friendly, helpful, negative loading); Trait Irritability (irritable, lacking patience); Verbal Trait Aggression (tending to express aggressive feelings in speech); and Physical Trait Aggression (tending to express aggressive feelings in action, such as getting into fights). Factor 3 includes scales assessing Extraversion; Impulsiveness (acting on the spur of the moment, nonplanning); Adventure Seeking (needing change and action); Detachment (socially withdrawn, avoidant of involvement, negative loading) [35].

Each subscale includes seven items. The response format is a four-point rating scale in which 1 denotes "does not apply at all" and 4 denotes "applies completely". Social Desirability and Detachment are included in the factors with reversed values. The SSP scores are transformed into $T$ scores with a mean of 50 and a standard deviation of 10 , based on a normative Swedish sex-stratified non-patient sample [33].

\section{Statistical analyses}

For descriptive purposes, sociodemographic, clinical variables and personality trait scores were compared between who continued and dropped out of the study, by use of Chi-square tests.

As the emphasis in this study was on development of PTSD or PTSS post abortion, the responders from all three assessments were categorized into four groups [7], depending on their PTSD or PTSS trajectories: 1) Women who had no PTSD/PTSS at baseline but met the criteria for PTSD/PTSS at least once at the 3- or 6month assessments were classified as having developed PTSD or PTSS. Women who had PTSS at baseline but met the criteria for PTSD at least once at the 3- or 6month assessments were also included in this group, as 
these women transitioned from a subthreshold PTSD to PTSD during the study course. The rationale for this strategy was to fully evaluate the abortion as a potentially triggering experience. 2) Women who recovered, i.e., had PTSD or PTSS at baseline but no longer met the criteria for PTSD or PTSS, at the 6-month assessments were classified as recovered. 3) Women who met criteria for PTSD or PTSS at all assessments were classified as unchanged. 4) Women who never fulfilled criteria for PTSD or PTSS at any assessment were used as a comparison group.

The binary analyses of sociodemographic and clinical variables were analyzed with Chi2- tests. One-way ANOVA, followed by Tukey's Honestly Significant Difference test, was used to compare personality trait scores between groups. These results were further subjected to a Bonferroni correction ( $p$-value $<0.004$ for the personality scales and $p$-value $<0.017$ for the personality factors).

Risk factors for development of PTSD/PTSS post abortion was analyzed by multiple logistic regression analysis. Besides the Neuroticism factor, all available sociodemographic and clinical variables including abortion method and place for abortion, were considered as potential covariates, see Table 2. The final model included statistical significant variables in the bivariate analyses $(p<0.05)$ and variables based on the literature. Final covariates included age (dichotomized as $<25$ and $\geq 25$, as most abortions in Sweden are performed in the age group 20 to 24 years followed by the age group 25 to 29 years [27, 28]. Educational level $(<12$ years vs. $\geq 12$ years, corresponding to completed high school or not), occupation (working full time, working part time, student, other occupation), experience of violence (yes or no), experience of sexual trauma (yes or no), alcohol use (yes or no), parity (yes or no) and counseling before the abortion (yes or no). In addition, previous abortion (yes or no) was included in the model, although it was not associated with PTSD development or Neuroticism in the bivariate analyses. However, prior studies have suggested that women with repeat abortions experience more adverse events, including violence, in their lives [36, 37], and would be expected to have higher levels of PTSD symptoms. Because of the close relationship between Neuroticism and mood disorders [16-19], anxiety and depression symptoms were not considered in the final analysis. The Neuroticism factor score was analyzed as a i) continuous variable, ii) categorized as above median vs. below median (reference) and iii) the highest quartile vs. below median (reference). SPSS Statistics for Windows, Version 20.0. (IBM Corp, Armonk, NY, USA) was used for all statistical analyses.

\section{Results}

Participants

Of the 1514 participating women at baseline, 13 were excluded because they chose not to have an abortion or had a second-trimester abortion. The SSP questionnaire was not completed by 122 women. Eighty-five women had not completed the entire SQ-PTSD questionnaire and could not be evaluated for presence of PTSD or PTSS; thus, 1294 women were available for analyses on Neuroticism-related personality traits in relation to PTSD or PTSS research diagnoses. Of the 1294 women who responded to the baseline questionnaire, 69 were never reported to the study center and consequently never received the follow-up questionnaire. Response rates were therefore $668 / 1225(54.5 \%)$ at the 3-month follow-up, and 576/1225 (47\%) at the 6-month assessment. Total numbers of responders over the two follow-up periods was 674, including six women who were responders at the 6-month assessment but were non-responders at the 3-month assessment.

Of the baseline responders, 92\% were native Swedes. Foreign born women most commonly originated from Asia (3\%), Europe (2\%), other Nordic countries (1\%), and South America (1\%). Ages ranged from 15 to 52 years, with a mean age of 28 and a median age of 27 years $(S D \pm 7.2)$. Almost $70 \%$ had less than 12 years of education, and the most common occupational statuses were full-time work or student (Table 1).

Because of the high number of dropouts in this cohort study an attrition analysis was conducted. The analysis showed that the dropouts to a higher extension were younger, had a lower level of education, were more often tobacco users, and had had a previous abortion more often than responders (Table 1).

\section{Sociodemographic data in relation to trajectories of PTSD or PTSS post abortion}

Forty-eight women developed PTSD or PTSS after the abortion; of these 21 at some point developed PTSD and 27 developed PTSS. Among women who developed PTSS, eight fulfilled criteria for re-experiencing, avoidance and hyperarousal (B-D criteria), ten fulfilled at least two, and nine women fulfilled at least one of these criteria.

In addition, 137 women recovered from their PTSD/ PTSS, and 25 women had an unchanged PTSD/PTSS status throughout the study course; while the majority ( $n=464)$ had no PTSD or PTSS at any of the assessment points. Sociodemographic data in relation to the PTSD and PTSS trajectories are given in Table 2. In brief, women who at some point had suffered from PTSD or PTSS displayed higher baseline levels of anxiety and depressive symptoms and had more often experienced violence and/or sexual trauma than the 
Table 1 Characteristics and personality trait T-scores of responders and dropouts at the first visit at the clinic (baseline) and at follow-up after the abortion

\begin{tabular}{|c|c|c|c|c|c|c|c|}
\hline \multirow[b]{2}{*}{ Variable } & \multirow{2}{*}{$\begin{array}{l}\text { Baseline } \\
\text { All } \\
(n=1294)\end{array}$} & \multicolumn{2}{|c|}{3 month follow up } & \multirow[b]{2}{*}{$p$-value } & \multicolumn{2}{|c|}{6 month follow up } & \multirow[b]{2}{*}{$p$-value } \\
\hline & & $\begin{array}{l}\text { Responders }^{a} \\
(n=668)\end{array}$ & $\begin{array}{l}\text { Dropouts }^{a} \\
(n=551)\end{array}$ & & $\begin{array}{l}\text { Responders } \\
(n=576)^{\mathrm{b}}\end{array}$ & $\begin{array}{l}\text { Dropouts } \\
(n=98)\end{array}$ & \\
\hline Age & & & & $<0.01$ & & & ns \\
\hline $15-19$ & $115(8.9)$ & $49(7.3)$ & $58(10.5)$ & & $41(7.1)$ & $8(8.2)$ & \\
\hline $20-24$ & $385(29.8)$ & $184(27.3)$ & 185 (33.6) & & $153(26.6)$ & 31 (31.6) & \\
\hline $25-34$ & $516(39.9)$ & $277(41.1)$ & $209(37.9)$ & & $239(41.5)$ & $38(38.8)$ & \\
\hline $35-52$ & $278(21.5)$ & $164(24.3)$ & 99 (18.0) & & $143(24.8)$ & $21(21.4)$ & \\
\hline Living alone & $328(26.2)$ & $160(24.3)$ & $146(27.8)$ & ns & $133(23.6)$ & $27(28.1)$ & ns \\
\hline Education $<12$ years & $885(68.9)$ & $423(63.0)$ & $416(76.3)$ & $<0.001$ & $352(61.4)$ & $71(72.4)$ & $<0.05$ \\
\hline Occupation & & & & ns & & & ns \\
\hline Working full time & $514(41.0)$ & $270(41.1)$ & $212(40.0)$ & & $225(40.1)$ & $45(46.9)$ & \\
\hline Working part time & $245(19.5)$ & $139(21.2)$ & $91(17.2)$ & & $128(22.8)$ & $11(11.5)$ & \\
\hline Student & 309 (24.6) & $158(24.0)$ & $137(25.8)$ & & $133(23.7)$ & $25(26.0)$ & \\
\hline Other occupation & $187(14.9)$ & $90(13.7)$ & $90(17.0)$ & & $75(13.4)$ & $15(15.6)$ & \\
\hline Anxiety symptoms & $544(42.4)$ & $257(38.4)$ & $255(46.8)$ & $<0.01$ & $217(37.9)$ & $40(41.7)$ & ns \\
\hline Depression symptoms & $404(31.5)$ & $197(29.4)$ & $180(33.0)$ & ns & $167(29.1)$ & $30(31.3)$ & ns \\
\hline Antidepressant use & $90(7.3)$ & $38(5.8)$ & $47(9.2)$ & $<0.05$ & $33(5.9)$ & $5(5.3)$ & ns \\
\hline Alcohol use & $1033(80.1)$ & $550(81.6)$ & $428(78.2)$ & ns & $466(80.9)$ & $84(85.7)$ & ns \\
\hline Tobacco use & $499(38.7)$ & $222(33.0)$ & $254(46.4)$ & $<0.001$ & $181(31.5)$ & $41(41.8)$ & $<0.05$ \\
\hline Foreign born & $104(8.1)$ & $41(6.1)$ & $49(9.0)$ & ns & $37(6.4)$ & $4(4.1)$ & ns \\
\hline No children & $672(56.0)$ & $350(54.8)$ & $281(56.1)$ & ns & $301(55.2)$ & $49(52.1)$ & ns \\
\hline Previous abortion & 448 (38.6) & $208(33.5)$ & $211(43.9)$ & $<0.001$ & $165(31.3)$ & $43(46.2)$ & $<0.01$ \\
\hline Abortion method & & & & ns & & & $<0.05$ \\
\hline Medical & $1002(81.9)$ & $543(83.4)$ & $418(82.1)$ & & $471(84.7)$ & $72(75.8)$ & \\
\hline Surgical & $221(18.1)$ & $108(16.6)$ & $91(17.9)$ & & $85(15.3)$ & $23(24.2)$ & \\
\hline Place of abortion & & & & ns & & & ns \\
\hline Home & $645(52.9)$ & $360(55.5)$ & $274(54.0)$ & & $310(55.9)$ & $50(53.2)$ & \\
\hline Clinic & $574(47.1)$ & $289(44.5)$ & $233(46.0)$ & & $245(44.1)$ & $44(46.8)$ & \\
\hline Counseling before abortion & $464(40.3)$ & $280(45.6)$ & $181(38.2)$ & $<0.05$ & $244(46.6)$ & $36(40.0)$ & ns \\
\hline Counseling after abortion & $32(2.8)$ & $18(2.9)$ & $11(2.3)$ & ns & $17(3.3)$ & $1(1.1)$ & ns \\
\hline \multicolumn{8}{|l|}{ Neuroticism factor } \\
\hline Somatic trait anxiety & $51.8 \pm 10.2$ & $50.8 \pm 9.9$ & $52.7 \pm 10.4$ & $<0.004$ & $50.5 \pm 9.7$ & $52.9 \pm 11.0$ & ns \\
\hline Psychic trait anxiety & $49.6 \pm 10.1$ & $49.4 \pm 10.1$ & $49.8 \pm 10.1$ & ns & $49.5 \pm 10.1$ & $48.9 \pm 10.1$ & ns \\
\hline Stress susceptibility & $52.8 \pm 11.3$ & $51.9 \pm 11.2$ & $53.7 \pm 11.5$ & $<0.004$ & $51.8 \pm 11.1$ & $52.4 \pm 11.6$ & ns \\
\hline Lack of assertiveness & $50.1 \pm 10.0$ & $50.6 \pm 10.3$ & $49.7 \pm 9.9$ & ns & $50.8 \pm 10.2$ & $49.2 \pm 10.6$ & ns \\
\hline Embitterment, & $54.1 \pm 12.2$ & $53.1 \pm 12.1$ & $55.3 \pm 12.3$ & $<0.004$ & $52.9 \pm 12.2$ & $54.0 \pm 11.4$ & ns \\
\hline Mistrust & $51.8 \pm 12.4$ & $50.4 \pm 12.0$ & $53.5 \pm 12.8$ & $<0.004$ & $50.4 \pm 12.1$ & $50.5 \pm 11.7$ & ns \\
\hline \multicolumn{8}{|l|}{ Aggressiveness factor } \\
\hline Social desirability & $49.5 \pm 10.4$ & $50.1 \pm 10.1$ & $49.2 \pm 10.7$ & ns & $50.2 \pm 10.2$ & $49.9 \pm 9.4$ & ns \\
\hline Trait irritability & $52.0 \pm 11.6$ & $51.1 \pm 11.6$ & $52.5 \pm 11.6$ & ns & $50.8 \pm 11.5$ & $53.0 \pm 11.9$ & ns \\
\hline Verbal trait aggression & $52.1 \pm 10.5$ & $51.1 \pm 10.3$ & $52.9 \pm 10.3$ & $<0.004$ & $50.9 \pm 10.3$ & $52.4 \pm 10.4$ & ns \\
\hline Physical trait aggression & $49.1 \pm 11.1$ & $47.8 \pm 10.7$ & $50.3 \pm 11.3$ & $<0.004$ & $47.6 \pm 10.7$ & $49.3 \pm 10.9$ & ns \\
\hline \multicolumn{8}{|l|}{ Extraversion factor } \\
\hline Impulsiveness & $53.0 \pm 10.2$ & $52.4 \pm 10.1$ & $53.5 \pm 10.3$ & ns & $52.0 \pm 9.9$ & $55.1 \pm 10.6$ & ns \\
\hline
\end{tabular}


Table 1 Characteristics and personality trait T-scores of responders and dropouts at the first visit at the clinic (baseline) and at follow-up after the abortion (Continued)

\begin{tabular}{|c|c|c|c|c|c|c|c|}
\hline \multirow[b]{2}{*}{ Variable } & \multirow{2}{*}{$\begin{array}{l}\text { Baseline } \\
\text { All } \\
(n=1294)\end{array}$} & \multicolumn{2}{|c|}{3 month follow up } & \multirow[b]{2}{*}{$p$-value } & \multicolumn{2}{|c|}{6 month follow up } & \multirow[b]{2}{*}{$p$-value } \\
\hline & & $\begin{array}{l}\text { Responders }^{a} \\
(n=668)\end{array}$ & $\begin{array}{l}\text { Dropouts }^{a} \\
(n=551)\end{array}$ & & $\begin{array}{l}\text { Responders } \\
(n=576)^{\mathrm{b}}\end{array}$ & $\begin{array}{l}\text { Dropouts } \\
(n=98)\end{array}$ & \\
\hline Adventure seeking & $52.5 \pm 9.2$ & $51.6 \pm 9.2$ & $53.3 \pm 9.2$ & $<0.004$ & $51.2 \pm 9.1$ & $54.0 \pm 8.9$ & ns \\
\hline Detachment & $48.1 \pm 9.4$ & $47.5 \pm 9.3$ & $48.7 \pm 9.5$ & ns & $47.6 \pm 9.4$ & $47.0 \pm 8.8$ & ns \\
\hline Neuroticism factor & $310 \pm 52$ & $306 \pm 52$ & $315 \pm 53$ & ns & $306 \pm 51$ & $308 \pm 54$ & ns \\
\hline Aggressive factor & $104 \pm 34$ & $100 \pm 33$ & $107 \pm 35$ & $<0.017$ & $99 \pm 33$ & $105 \pm 32$ & ns \\
\hline Extraversion factor & $57 \pm 19$ & $57 \pm 19$ & $58 \pm 19$ & ns & $56 \pm 19$ & $62 \pm 19$ & $<0.017$ \\
\hline
\end{tabular}

The bivariate analysis were performed by Chi2 test. Data are displayed in numbers ( $\mathrm{n}$ ) and percentages (\%). Frequencies are given in relation to available information or responses. Missing information was prevalent in $0.1 \%$ (age) $-13 \%$ (counselling after abortion). The personality trait scores were analysed by Independent t-test. Data are displayed in mean $(M)$ and Standard Deviation $( \pm \mathrm{SD})$

${ }^{\mathrm{a}} 69$ participants at baseline were not dropouts; they were never asked to participate at follow-up and therefore were excluded from the analyses

${ }^{\mathrm{b}}$ Including 6 responders who were non-responders at the 3-month follow-up

${ }^{*} p<0.004$ for personality trait scores and $p<0.017$ for personality factors, according to independent T-tests and Bonferroni correction

comparison group. In addition, women who recovered and those who were unchanged in their status of PTSD/ PTSS post abortion used more antidepressant medication than the comparison group. Women who developed PTSD/PTSS post abortion were to a greater extent young, had no children, had higher levels of anxiety and depressive symptoms, were more likely to be tobacco users but were drinking alcohol less often, and were in need of counselling before abortion more often compared with the comparison group (Table 2).

\section{Personality trait scores}

Further attrition analyses by use of the pre-abortion personality assessments was performed (Table 1). Compared with responders, the dropouts at the three months assessment had slightly but significantly higher scores on Somatic Trait Anxiety, Stress Susceptibility Embitterment, Mistrust, Verbal and Physical Trait Aggression, and Adventure Seeking. There were no differences in personality traits between dropout and responders at the six-month assessment.

Personality trait scores in relation to the baseline, preabortion assessment of PTSD and PTSS are given in Table 3. As expected, women with PTSD or PTSS displayed higher scores than did the comparison group on almost all personality traits associated with Neuroticism, particularly Embitterment and Mistrust. The highest personality trait scores within the Neuroticism factor were found in women who fulfilled a research diagnosis of PTSD, whereas women with PTSS had intermediate scores, and the comparison group had scores close to the population mean ( $T$ score of 50$)$. In addition, a number of personality traits associated with Aggressiveness and Extraversion was significantly higher in women with pre-abortion PTSD than in the comparison group (Table 3 ).
Personality trait scores and PTSD or PTSS post abortion

Table 4 displays the baseline personality traits in relation to the PTSD and PTSS post abortion trajectories. Women who developed PTSD/PTSS post abortion had higher scores on Somatic Trait Anxiety, Psychic Trait Anxiety, Stress Susceptibility, and Embitterment (Table 4). Similarly, women who recovered and women who remained unchanged as to their PTSD/ PTSS status throughout the study had higher scores than the comparison group on most of the neurotic personality traits. In fact, women with unchanged PTSD/PTSS status had the highest scores of Embitterment, and differed on this item from all other groups. Furthermore, women with recovered or unchanged PTSD/PTSS status also had higher scores on several of the personality traits within the Aggressiveness and Extraversion factors (Table 4).

High Neuroticism scores (continuous or categorized) and previous experience of violence were the strongest predictors for the development of PTSD/PTSS post abortion (Table 5). This finding was mainly driven by women who developed PTSD $(n=21)$, where the AOR for high Neuroticism scores and previous experience of violence were 6.73 (CI 95\% 1.45-31.2) and 11.09 (CI 95\% 3.00-41.0), respectively. Among women who developed PTSS post abortion, no significant predictors were found, data not shown.

\section{Discussion}

The most important finding was that women who developed PTSD or PTSS after the abortion scored higher on Neuroticism-related personality traits than did the comparison group who did not meet criteria for PTSD or PTSS prior to or after the abortion. Very high scores on the Neuroticism factor, together with experiences of 
Table 2 Sociodemographic data and personality trait T-scores in relation to post-abortion PTSS/PTSD trajectories $(n=674)$

\begin{tabular}{|c|c|c|c|c|c|c|c|}
\hline \multirow[t]{2}{*}{ Variable } & \multirow{2}{*}{$\begin{array}{l}\text { Comparison } \\
\text { group } \\
n=464 \\
n \%\end{array}$} & \multirow{2}{*}{$\begin{array}{l}\text { Developed } \\
\text { PTSD/PTSS } \\
n=48 \\
n \%\end{array}$} & \multirow[b]{2}{*}{$p$-value } & \multirow{2}{*}{$\begin{array}{l}\text { Recovered } \\
n=137 \\
n \%\end{array}$} & \multirow[b]{2}{*}{$p$-value } & \multirow{2}{*}{$\begin{array}{l}\text { Unchanged } \\
n=25 \\
n \%\end{array}$} & \multirow[b]{2}{*}{$p$-value } \\
\hline & & & & & & & \\
\hline \multicolumn{8}{|l|}{ Variable } \\
\hline Age & & & $<0.01$ & & ns & & ns \\
\hline $15-19$ & $28(6.0)$ & $6(12.5)$ & & $11(8.0)$ & & $4(16.0)$ & \\
\hline $20-24$ & 119 (25.6) & $22(45.8)$ & & $39(28.5)$ & & $4(16.0)$ & \\
\hline $25-34$ & $194(41.8)$ & $15(31.3)$ & & $54(39.4)$ & & $14(56.0)$ & \\
\hline $35-52$ & $123(26.5)$ & $5(10.4)$ & & $33(24.1)$ & & $3(12)$ & \\
\hline Living alone & $108(23.7)$ & $16(34.0)$ & ns & $30(22.7)$ & ns & $6(24.0)$ & ns \\
\hline Education $<12$ years & $275(59.5)$ & $34(72.3)$ & ns & $95(69.3)$ & $<0.05$ & $19(76.0)$ & ns \\
\hline Occupation & & & $<0.05$ & & ns & & ns \\
\hline Working full time & $205(45.3)$ & $10(22.2)$ & & 49 (36.6) & & $6(24.0)$ & \\
\hline Working part time & $92(20.3)$ & $12(26.7)$ & & $30(22.4)$ & & $5(20.0)$ & \\
\hline Student & $98(21.6)$ & $15(33.3)$ & & 37 (27.6) & & $8(32.0)$ & \\
\hline Other occupation & $58(12.8)$ & $8(17.8)$ & & $18(13.4)$ & & $6(24.0)$ & \\
\hline Sexual trauma & $12(2.6)$ & $5(10.4)$ & $<0.01$ & $39(28.5)$ & $<0.001$ & $9(36.0)$ & $<0.001$ \\
\hline Experience of violence & $79(17.0)$ & 19 (39.6) & $<0.001$ & $82(59.9)$ & $<0.001$ & $18(72.0)$ & $<0.001$ \\
\hline Anxiety symptoms & $127(27.5)$ & $31(64.6)$ & $<0.001$ & $80(59.3)$ & $<0.001$ & $19(76.0)$ & $<0.001$ \\
\hline Depression symptoms & $107(23.2)$ & $18(37.5)$ & $<0.05$ & $52(38.5)$ & $<0.001$ & $20(80.0)$ & $<0.001$ \\
\hline Antidepressant use & $15(3.3)$ & $4(9.3)$ & ns & $16(12.0)$ & $<0.001$ & $3(12.0)$ & $<0.05$ \\
\hline Alcohol use & 388 (83.6) & $34(70.8)$ & $<0.05$ & $110(80.3)$ & ns & $18(72.0)$ & ns \\
\hline Tobacco use & $138(29.8)$ & 16 (33.3) & ns & $52(38.0)$ & ns & $16(64.0)$ & $<0.001$ \\
\hline Foreign born & $25(5.4)$ & $3(6.3)$ & ns & $12(8.8)$ & ns & $1(4.0)$ & ns \\
\hline No children & $239(53.6)$ & $29(70.7)$ & $<0.05$ & $71(55.5)$ & ns & $11(45.8)$ & ns \\
\hline Previous abortion & $135(31.3)$ & $14(34.1)$ & ns & $47(38.2)$ & ns & $12(48.0)$ & ns \\
\hline Abortion method & & & ns & & ns & & ns \\
\hline Medical & $377(83.8)$ & $35(79.5)$ & & $110(83.3)$ & & $21(84.0)$ & \\
\hline Surgical & $73(16.2)$ & $9(20.5)$ & & $22(16.7)$ & & $4(16.0)$ & \\
\hline Place of abortion & & & ns & & ns & & ns \\
\hline Home & $257(57.2)$ & $22(52.4)$ & & $68(51.1)$ & & $13(52.0)$ & \\
\hline Clinic & $192(42.8)$ & $20(47.6)$ & & 65 (48.9) & & $12(48.0)$ & \\
\hline Counseling before abortion & $175(41.8)$ & $25(58.1)$ & $<0.05$ & $69(53.9)$ & $<0.05$ & $11(45.8)$ & ns \\
\hline Counseling after abortion & $10(2.4)$ & $3(7.0)$ & ns & $4(3.1)$ & ns & $1(4.2)$ & ns \\
\hline
\end{tabular}

violence, were associated with increased odds of developing PTSD or PTSS after the abortion. This finding was driven by the women who developed PTSD, whereas the risk factor profile for development of PTSS-only could not be determined.

As expected, women with PTSD at the pre-abortion assessment displayed higher scores than did the comparison group on almost all personality traits associated with Neuroticism, particularly Embitterment and Mistrust [13, 22]. Also, not surprisingly, the women who dropped out of the study scored higher on some of the Neuroticism-related personality traits than did women who responded to the follow-up questionnaires. This finding is in line with the dropout analyses in this cohort, which suggest that women with PTSD [7], and/or those with more pronounced anxiety symptoms at baseline are less likely to continue in this longitudinal study. However, although the high dropout rate of the study may have influenced the overall prevalence of PTSD or PTSS after the abortion [7], the influence of Neuroticism on PTSD or PTSS is likely unaffected by the drop-outs.

Our findings add understanding the reasons that some women develop mental health problems after an abortion by demonstrating that the individual level of 
Table 3 Personality trait T scores of baseline responders on the Swedish universities Scales of Personality $(n=1294)$

\begin{tabular}{|c|c|c|c|c|c|}
\hline \multirow[t]{2}{*}{ Variable } & $\begin{array}{l}\text { Comparison group } \\
n=899\end{array}$ & \multirow{2}{*}{$\begin{array}{l}\text { PTSD at baseline } \\
n=89 \\
M \pm S D\end{array}$} & \multirow[b]{2}{*}{$p$-value } & \multirow{2}{*}{$\begin{array}{l}\text { PTSS at baseline } \\
n=306 \\
M \pm S D\end{array}$} & \multirow[b]{2}{*}{$p$-value } \\
\hline & $M \pm S D$ & & & & \\
\hline \multicolumn{6}{|l|}{ Neuroticism factor } \\
\hline Somatic Trait Anxiety & $49.6 \pm 9.5$ & $63.1 \pm 9.4^{a}$ & $<0.001$ & $54.8 \pm 9.4$ & $<0.001$ \\
\hline Psychic Trait Anxiety & $47.9 \pm 9.7$ & $58.8 \pm 9.8^{a}$ & $<0.001$ & $52.1 \pm 9.4$ & $<0.001$ \\
\hline Stress Susceptibility & $51.0 \pm 10.7$ & $62.4 \pm 11.3^{a}$ & $<0.001$ & $55.3 \pm 11.1$ & $<0.001$ \\
\hline Lack of Assertiveness & $49.5 \pm 9.7$ & $53.3 \pm 11.5$ & 0.002 & $50.9 \pm 10.4$ & ns \\
\hline Embitterment & $51.1 \pm 10.7$ & $70.2 \pm 12.7^{\mathrm{a}}$ & $<0.001$ & $58.4 \pm 11.1$ & $<0.001$ \\
\hline Mistrust & $49.4 \pm 11.6$ & $64.3 \pm 11.5^{\mathrm{a}}$ & $<0.001$ & $55.1 \pm 12.1$ & $<0.001$ \\
\hline \multicolumn{6}{|l|}{ Aggressiveness factor } \\
\hline Social Desirability (negative loading) & $49.9 \pm 10.1$ & $47.8 \pm 12.5$ & ns & $49.1 \pm 10.5$ & ns \\
\hline Trait Irritability & $50.6 \pm 11.4$ & $58.6 \pm 11.6^{a}$ & $<0.001$ & $54.1 \pm 10.9$ & $<0.001$ \\
\hline Verbal Trait Aggression & $51.3 \pm 10.3$ & $56.1 \pm 11.0$ & $<0.001$ & $53.4 \pm 10.5$ & ns \\
\hline Physical Trait Aggression & $48.1 \pm 10.6$ & $53.8 \pm 12.3$ & $<0.001$ & $50.8 \pm 11.8$ & 0.001 \\
\hline \multicolumn{6}{|l|}{ Extraversion factor } \\
\hline Impulsiveness & $51.9 \pm 9.8$ & $56.2 \pm 11.6$ & $<0.001$ & $55.3 \pm 10.4$ & $<0.001$ \\
\hline Adventure Seeking & $52.1 \pm 9.1$ & $53.0 \pm 10.9$ & ns & $53.7 \pm 9.1$ & ns \\
\hline Detachment (negative loading) & $47.6 \pm 9.1$ & $52.4 \pm 9.9^{a}$ & $<0.001$ & $48.5 \pm 9.8$ & ns \\
\hline Neuroticism factor & $299 \pm 48$ & $372 \pm 46^{a}$ & $<0.001$ & $327 \pm 47$ & $<0.001$ \\
\hline Aggressiveness factor & $100 \pm 33$ & $121 \pm 37$ & $<0.001$ & $109 \pm 34$ & $<0.001$ \\
\hline Extraversion factor & $56 \pm 19$ & $57 \pm 23$ & ns & $61 \pm 20$ & ns \\
\hline
\end{tabular}

One-way ANOVA with post hoc Tukey HSD test. $M=$ Mean; SD = Standard Deviation. The $a$-level was adjusted with Bonferroni correction; $a=0.004$ for the individual personality traits and $\alpha=0.017$ for the personality factors. Unless otherwise stated, $p$-values are for comparisons with the comparison group a $p<0.001-0.002$ in comparison with women who had PTSS at baseline

Neuroticism-related personality traits may contribute to post abortion vulnerability to PTSD [13]. Among the many explanatory factors assessed, very high levels of Neuroticism emerged as the most influential factors for PTSD or PTSS post abortion. The findings is in accordance with previous studies indicating that high scores of Neuroticism is associated with PTSD [13, 16, 23] especially in women [22, 38]. However, contradictory results by Engelhart, et al. [39] demonstrate that pretrauma Neuroticism was not significantly associated with PTSD symptoms after pregnancy loss. Instead, Engelhart and colleagues suggest that PTSD-arousal symptoms may overlap with Neuroticism [39].

Neuroticism is an important predisposing factor for major depression and anxiety disorders, including PTSD [16-24]. In the abortion context, this finding adds further support to the argument that the most consistent predictor of mental disorders after abortion is a preexisting mental disorder [2-4]. Clearly, according to our results, not only pre-existing mental disorders but also personality features that may render a person susceptible to mental ill-health are of relevance. Extrapolating further to what is known in the field of depression and anxiety disorders, genetic factors shared with Neuroticism are commonly acknowledged to account for between onethird and one-half of the genetic risk of lifetime major depression, generalized anxiety disorder, panic disorder, and virtually all phobic disorders [17, 19, 40, 41]. Most well-known of these genetic factors is the short version of the serotonin transporter gene, which, among its many other effects, has been found to moderate the influence of stressful life events on depression [42]. Although less is known about the relationships between PTSD, Neuroticism, and shared genetic or environmental factors, we speculate that risk of post abortion mental health problems may also be influenced by genetic vulnerability traits [43] .

Moreover, exposure to violence was associated with increased odds of developing PTSD or PTSS after the abortion. This finding is in line with previous studies demonstrating that the highest risk of PTSD is associated with assaultive violence. This type of violence is more common among women than men [12], and seems more strongly associated with PTSD in females than in males [13].

An unexpected finding in our study, was that sexual trauma not was independently associated with development of PTSD post abortion. In contrast, populationbased studies have suggested that sexual abuse is the 
Table 4 Personality trait T-scores in relation to post-abortion PTSS/PTSD trajectories $(n=674)$

\begin{tabular}{|c|c|c|c|c|c|c|c|}
\hline \multirow[t]{2}{*}{ Variable } & \multirow{2}{*}{$\begin{array}{l}\text { Comparison group }(n=464) \\
M \pm S D\end{array}$} & \multirow{2}{*}{$\begin{array}{l}\text { Developed } \\
\text { PTSD/PTSS } \\
(n=48) \\
M \pm S D\end{array}$} & \multirow[b]{2}{*}{$p$-value } & \multirow{2}{*}{$\begin{array}{l}\text { Recovered } \\
(n=137) \\
M \pm S D\end{array}$} & \multirow[b]{2}{*}{$p$-value } & \multirow{2}{*}{$\begin{array}{l}\text { Unchanged } \\
(n=25) \\
M \pm S D\end{array}$} & \multirow[b]{2}{*}{$p$-value } \\
\hline & & & & & & & \\
\hline \multicolumn{8}{|l|}{ Neuroticism factor } \\
\hline Somatic trait anxiety & $48.7 \pm 9.2$ & $55.0 \pm 9.6$ & $<0.001$ & $55.1 \pm 10.0$ & $<0.001$ & $59.5 \pm 9.6$ & $<0.001$ \\
\hline Psychic trait anxiety & $47.4 \pm 9.5$ & $54.3 \pm 8.5$ & $<0.001$ & $53.2 \pm 10.5$ & $<0.001$ & $56.3 \pm 9.4$ & $<0.001$ \\
\hline Stress susceptibility & $49.6 \pm 10.0$ & $55.9 \pm 11.0$ & $<0.004$ & $56.9 \pm 12.6$ & $<0.001$ & $58.9 \pm 11.0$ & $<0.001$ \\
\hline Lack of assertiveness & $49.7 \pm 9.6$ & $54.6 \pm 10.9$ & ns & $55.5 \pm 10.6$ & ns & $51.1 \pm 11.6$ & ns \\
\hline Embitterment, & $50.1 \pm 10.4$ & $56.6 \pm 11.2$ & $<0.001$ & $59.2 \pm 12.8$ & $<0.001$ & $68.5 \pm 12.7^{a, b}$ & $<0.001$ \\
\hline Mistrust & $47.9 \pm 11.0$ & $53.7 \pm 11.7$ & ns & $55.7 \pm 12.7$ & $<0.001$ & $61.5 \pm 12.1$ & $<0.001$ \\
\hline \multicolumn{8}{|l|}{ Aggressiveness factor } \\
\hline Social desirability & $50.2 \pm 9.7$ & $51.4 \pm 11.9$ & ns & $49.5 \pm 10.6$ & ns & $50.3 \pm 10.5$ & ns \\
\hline Trait irritability & $49.6 \pm 11.4$ & $53.3 \pm 9.2$ & ns & $54.5 \pm 11.6$ & $<0.001$ & $56.3 \pm 11.8$ & ns \\
\hline Verbal trait aggression & $50.1 \pm 10.0$ & $50.6 \pm 9.1$ & ns & $53.4 \pm 11.1$ & ns & $57.7 \pm 10.5$ & $<0.004$ \\
\hline Physical trait aggression & $46.5 \pm 9.7$ & $48.2 \pm 11.3$ & ns & $50.9 \pm 12.4$ & $<0.001$ & $54.2 \pm 11.6$ & $<0.004$ \\
\hline \multicolumn{8}{|l|}{ Extraversion factor } \\
\hline Impulsiveness & $51.1 \pm 9.3$ & $53.2 \pm 12.2$ & ns & $55.5 \pm 10.6$ & $<0.001$ & $58.5 \pm 11.1$ & $<0.004$ \\
\hline Adventure seeking & $51.3 \pm 8.8$ & $51.4 \pm 9.3$ & ns & $51.8 \pm 10.1$ & ns & $57.6 \pm 7.6$ & ns \\
\hline Detachment & $47.2 \pm 8.8$ & $50.0 \pm 10.9$ & ns & $47.7 \pm 10.1$ & ns & $48.3 \pm 9.3$ & ns \\
\hline Neuroticism factor & $293 \pm 46$ & $330 \pm 43$ & $<0.001$ & $332 \pm 54$ & $<0.001$ & $356 \pm 49$ & $<0.001$ \\
\hline Aggressive factor & $96 \pm 31$ & $101 \pm 32$ & ns & $109 \pm 36$ & $<0.001$ & $118 \pm 34$ & $<0.017$ \\
\hline Extraversion factor & $55 \pm 18$ & $55 \pm 22$ & ns & $60 \pm 20$ & ns & $68 \pm 20$ & $<0.017$ \\
\hline
\end{tabular}

One-way ANOVA with post hoc Tukey HSD test. $M=$ Mean; SD = Standard Deviation. The a-level was adjusted with Bonferroni correction; $a=0.004$ for the individual personality traits and $a=0.017$ for the personality factors. Unless otherwise stated, $p$-values for comparisons with the comparison group are reported ${ }^{a} p<0.001$ in comparison with women who developed PTSD/PTSS

${ }^{a} p<0.001$ in comparison with women who recovered from PTSD/PTSS

traumatic exposure which most frequently lead to PTSD [13]. Intimate partner violence, where sexual violence is included, is more common among women seeking abortion than in other gynecology patients [36, 44], but Swedish women who request induced abortion are more likely to report exposure to physical violence than sexual violence $[14,36]$. Potentially, sexual trauma is underreported in our study, weakening the hypothesized association. Taken together, these findings stress the importance for health care professionals to approach women seeking abortion with questions of experiences of violence exposure.

Medical abortions in home settings are increasing in Sweden [27]. From a clinical point of view concerns has been raised that severe pain during the medical abortion may qualify as a traumatic experience. Clearly, neither the abortion method nor the place in which the abortion occurred contributed to this risk, and as previously shown by us, very few women who developed PTSD after the abortion did so because of trauma events that were related to the abortion per se [7]. Furthermore, similar results have been reported from studies of burn victims, where post-injury psychological health and PTSD were associated with baseline symptoms, avoidant coping, and Neuroticism-related personality traits, rather than severity of the burn $[45,46]$.

The personality trait that most prominently distinguished between patients who developed or remained unchanged in their PTSD status was Embitterment, which can be defined as persistent feelings of being insulted, a loser, or revengeful but helpless [47]. Although it is possible that women with PTSD or PTSS have reacted with embitterment to critical events in normal life [47], other explanations also include a greater degree of hostility among individuals with PTSD and PTSS [48] or self-blaming for not having been competent enough to avoid the trauma $[47,48]$ (feelings that may, in turn, lead to embitterment) [47]. Embitterment could also be considered to be associated with negative alterations in cognitions and mood that are associated with the trauma, which is described in DSM-5 as a new symptom cluster for PTSD. This D-cluster contains descriptions of negative beliefs or expectations about one self, others or the world, distorted blame of self or others and persistent negative emotional state [49]. Potentially, Embitterment captures some of the aspects of the new symptom cluster [39, 49]. 
Table 5 The association between age, neuroticism, alcohol use and counseling before abortion among women who developed PTSD/PTSS after the abortion $(n=48)$

\begin{tabular}{|c|c|c|c|c|}
\hline \multirow[b]{2}{*}{ Variable } & \multicolumn{2}{|c|}{ Unadjusted } & \multicolumn{2}{|c|}{ Adjusted for demographic variables } \\
\hline & $\overline{\mathrm{OR}}$ & $95 \% \mathrm{Cl}$ & $\mathrm{OR}$ & $95 \% \mathrm{Cl}$ \\
\hline Age & 0.92 & $0.87-0.96$ & 0.98 & $0.89-1.07$ \\
\hline Education $<12$ years & 1.78 & $0.91-3.46$ & 1.12 & $0.46-2.73$ \\
\hline \multicolumn{5}{|l|}{ Occupation } \\
\hline Working full time & 1 & & 1 & \\
\hline Working part time & 2.67 & $1.12-6.41$ & 2.31 & $0.80-6.65$ \\
\hline Student & 3.13 & $1.36-7.24$ & 2.25 & $0.72-7.03$ \\
\hline Other occupation & 2.83 & $1.07-7.49$ & 1.46 & $0.42-5.17$ \\
\hline Sexual trauma & 4.38 & $1.48-13.0$ & 1.69 & $0.29-9.80$ \\
\hline Experience of violence & 3.19 & $1.71-5.98$ & 2.72 & $1.21-6.12$ \\
\hline Alcohol use & 0.48 & $0.24-0.93$ & 0.52 & $0.23-1.18$ \\
\hline No children & 2.09 & $1.04-4.21$ & 1.32 & $0.42-4.13$ \\
\hline \multicolumn{5}{|l|}{ Previous abortions } \\
\hline 0 & 1 & & 1 & \\
\hline 1 & 1.23 & $0.57-2.64$ & 1.32 & $0.55-3.18$ \\
\hline 2 & 1.06 & $0.30-3.70$ & 0.71 & $0.14-3.63$ \\
\hline 3 or more & 0.73 & $0.09-5.75$ & 0 & n.c. \\
\hline Counseling before abortion & 1.94 & $1.03-3.66$ & 1.20 & $0.56-2.56$ \\
\hline \multicolumn{5}{|l|}{ Neuroticism } \\
\hline Continuous & 1.02 & $1.01-1.02$ & $1.01^{\mathrm{a}}$ & $1.003-1.02$ \\
\hline High scores (above median vs. below median) & 3.60 & $1.88-6.89$ & $2.36^{\mathrm{a}}$ & $1.08-5.16$ \\
\hline Very high scores (highest quartile vs. below median) & 4.81 & $2.26-10.22$ & $3.22^{\mathrm{a}}$ & $1.22-8.45$ \\
\hline
\end{tabular}

$O R=$ odds ratio; $\mathrm{Cl}=$ confidence interval

adjusted for all variables in the table, except the other neuroticism variables

Women who recovered or remained unchanged in their PTSD and PTSS status also had higher scores on some of the Aggressive personality traits. Anger and aggression are common symptoms in PTSD, among United States veterans as well as the general population $[42,48]$. Previous study results indicate that the three PTSD symptom clusters of re-experience, avoidance, and hyperarousal from DSM-IV, may differently affect aggressive symptoms, where hyperarousal alone has been shown to be strongly associated with aggression $[42,50]$. In DSM-5 the E- symptom cluster, alternations in arousal and reactivity that are associated with the traumatic event, with additional symptoms such as aggressive, reckless and self-destructive behavior has been taken to account [49]. So in addition, aggressiveness as well as embitterment might represent aspects where Neuroticism overlap with PTSD in the new DSM criteria [39]. Although additional knowledge for identifying persons at risk for post abortion PTSD might be gained by analyses of individual personality traits, PTSD symptom clusters, and the different ways posttraumatic distress may be expressed, the present study included too few women who actually developed PTSD following the abortion to allow such analyses. In addition, further research is also needed to define what interventions health care providers can offer to support women optimally.

As already mentioned, a major limitation of the study was the high dropout rate. Although women who appeared to be at risk for PTSD dropped out at a higher rate, this is unlikely to have influenced the overall relationship between Neuroticism and PTSD in the present study. Another limitation was the design of the questionnaire. The SSP inventory contains 91 items and was placed at the end of the questionnaire. As a consequence, some women did not complete the entire inventory, thereby further limiting the study sample at hand. Yet another limitation is that childhood trauma was not inventoried. Such measure would be relevant, as childhood trauma is related both to development of PTSD and Neuroticism [51,52]. The homogeneity of the sample, consisting of a majority of Swedish natives is also a limitation of the generalizability of the study. Furthermore, the use of self- reported inventories has 
several limitations [53]. In the present study the research diagnosis of PTSD was based on self-reports from the inventory SQ-PTSD. The best way to evaluate a PTSD diagnosis is with the Clinician Administrated PTSD Scale (CAPS) [54], but this was not practical in the present study. However, the reliability and validity as well as the sensitivity and specificity of the SQ-PTSD have been tested with satisfactory results [11].

Notably, the study also has several strengths, such as the Swedish context where abortion has been accepted for almost half a century, and where the resistance to abortion is low and free of stigmatization compared to many other countries. The setting is somewhat ideal, free from confounders such as anti-abortion protesters, which may interfere and lead to negative experiences of the abortion.

\section{Conclusion}

Findings in this study have strengthened the argument that the most consistent predictor of mental disorders after abortion is a pre-existing psychiatric disorder with which women present at the abortion clinic. We have shown that high scores on Neuroticism-related personality traits influence the risk of PTSD or PTSS post abortion. As expected exposure to violence also strongly influenced the risk of PTSD or PTSS after abortion

\section{Abbreviations}

Cl: Confidence Interval; DSM-5: The Diagnostic and Statistical Manual of Mental Disorders, Fifth edition; DSM-IV: The Diagnostic and Statistical Manual of Mental Disorders, Fourth edition; PTSD: Posttraumatic Stress Disorder; PTSS: Posttraumatic Stress Symptoms; SQ-PTSD: The Screen QuestionnairePosttraumatic Stress Disorder; SSP: The Swedish universities Scales of Personality

\section{Acknowledgments}

The authors wish to thank all the women for their participation in this study. We will also thank the research nurses who made this study possible by recruiting the participation women.

\section{Funding}

Funding for this project was provided by the Marianne and Marcus Wallenberg Foundation, the Medical Faculty of Uppsala Universities, the Family Planning Foundation at Uppsala University, the Regional Research Committees of Uppsala and Örebro Counties Councils and Sophiahemmet Foundation.

\section{Availability of data and materials}

The datasets analyzed during the current study will be available from the corresponding author on reasonable request.

\section{Authors' contributions}

$\mathrm{IWL}$; data collection, analysis and interpretation of data, drafting the manuscript, responsibility for the final preparation of the article. ISP; research idea, design, contributed to data analysis, interpretation, manuscript preparation and critically edited the final manuscript. LE; involved in interpretation of data and reviewed the manuscript. SG; interpretation of data, preparation of the final manuscript. ÖF; research idea, design and reviewed the manuscript. $\mathrm{LH}$; involved in data collection and reviewed the manuscript. UH; research idea, design and reviewed the manuscript. ASS; research idea, design, interpretation of data and preparation of the final manuscript. All authors read and approved of the final version of the manuscript.

\section{Competing interest}

The authors declare that they have no competing interests.

Ethics approval and consent to participate

The study was approved by the Central Ethical Review Board of Uppsala University, Sweden, dnr 2009/012 (approval date 25 February 2009). Informed written consent was obtained from all participants at recruitment.

Consent for publication

Not applicable

\section{Publisher's Note}

Springer Nature remains neutral with regard to jurisdictional claims in published maps and institutional affiliations.

\section{Author details}

${ }^{1}$ Department of Women's and Children's Health, Uppsala University, -751 85 Uppsala, SE, Sweden. 'Sophiahemmet University, Box 5605, - 11486 Stockholm, SE, Sweden. ${ }^{3}$ Department of Neuroscience/Psychiatry, Uppsala University, -75185 Uppsala, SE, Sweden. ${ }^{4}$ Department of Clinical Science, Intervention and Technology, Karolinska Institute, -171 77 Stockholm, SE, Sweden. ${ }^{5}$ Department of Psychology, Uppsala University, Box 1225, -751 42 Uppsala, SE, Sweden. ${ }^{6}$ Department of Clinical Science and Education, Karolinska Institute, -118 83 Stockholm, SE, Sweden.

Received: 7 November 2016 Accepted: 8 August 2017

Published online: 02 October 2017

\section{References}

1. Kero A, Högberg U, Lalos A. Wellbeing and mental growth-long-term effects of legal abortion. Soc Sci Med. 2004;58(12):2559-69.

2. Major B, Cozzarelli C, Cooper ML, Zubek J, Richards C, Wilhite M, Gramzow RH. Psychological responses of women after first-trimester abortion. Arch Gen Psychiatry. 2000;57(8):777-84.

3. Major B, Appelbaum M, Beckman L, Dutton MA, Russo NF, West C. Abortion and mental health: evaluating the evidence. Am Psychol. 2009;64(9):863-90.

4. Robinson GE, Stotland NL, Russo NF, Lang JA, Occhiogrosso M. Is there an "abortion trauma syndrome"? Critiquing the evidence Harv Rev Psychiatry. 2009;17(4):268-90.

5. Coleman PK. Abortion and mental health: quantitative synthesis and analysis of research published 1995-2009. Br J Psychiatry. 2011;199(3):180-6.

6. Steinberg JR, Trussell J, Hall KS, Guthrie K. Fatal flaws in a recent metaanalysis on abortion and mental health. Contraception. 2012;86(5):430-7.

7. Wallin Lundell I, Georgsson Ohman S, Frans O, Helstrom L, Hogberg U, Nyberg S, Sundstrom Poromaa I, Sydsjo G, Ostlund I, Skoog Svanberg A Posttraumatic stress among women after induced abortion: a Swedish multi-centre cohort study. BMC Womens Health. 2013:13:52.

8. Tolin DF, Foa EB. Sex differences in trauma and posttraumatic stress disorder: a quantitative review of 25 years of research. Psychol Bull. 2006;132(6):959-92.

9. Christiansen DM, Elklit A. Risk factors predict post-traumatic stress disorder differently in men and women. Ann General Psychiatry. 2008:7:24.

10. Kessler RC, Sonnega A, Bromet E, Hughes M, Nelson CB. Posttraumatic stress disorder in the National Comorbidity Survey. Arch Gen Psychiatry. 1995; 52(12):1048-60.

11. Frans Ö, Rimmö P-A, Åberg L, Fredrikson M. Trauma exposure and posttraumatic stress disorder in the general population. Acta Psychiatr Scand. 2005:111(4):291-0

12. Breslau N, Kessler RC, Chilcoat HD, Schultz LR, Davis GC, Andreski P. Trauma and posttraumatic stress disorder in the community: the 1996 Detroit area survey of trauma. Arch Gen Psychiatry. 1998;55(7):626-32.

13. Perrin M, Vandeleur CL, Castelao E, Rothen S, Glaus J, Vollenweider P, Preisig M. Determinants of the development of post-traumatic stress disorder, in the general population. Soc Psychiatry Psychiatr Epidemiol. 2013;

14. Tinglof S, Hogberg U, Lundell IW, Svanberg AS. Exposure to violence among women with unwanted pregnancies and the association with posttraumatic stress disorder, symptoms of anxiety and depression. Sex Reprod Healthc. 2015;6(2):50-3.

15. Caspi A, Roberts BW, Shiner RL. Personality development: stability and change. Annu Rev Psychol. 2005;56:453-84. 
16. Hettema JM, Prescott CA, Kendler KS. Genetic and environmental sources of covariation between generalized anxiety disorder and neuroticism. Am J Psychiatry. 2004;161(9):1581-7.

17. Kendler KS, Gatz M, Gardner CO, Pedersen NL. Personality and major depression: a Swedish longitudinal, population-based twin study. Arch Gen Psychiatry. 2006;63(10):1113-20.

18. Ormel J, Oldehinkel AJ, Vollebergh W. Vulnerability before, during, and after a major depressive episode: a 3-wave population-based study. Arch Gen Psychiatry. 2004;61(10):990-6.

19. Kendler KS, Kuhn J, Prescott CA. The interrelationship of neuroticism, sex and stressful life events in the prediction of episodes of major depression. Am J Psychiatry. 2004;161(4):631-6.

20. Bienvenu OJ, Nestadt G, Samuels JF, Costa PT, Howard WT, Eaton WW. Phobic, panic, and major depressive disorders and the five-factor model of personality. J Nerv Ment Dis. 2001;189(3):154-61.

21. Bienvenu OJ, Hettema JM, Neale MC, Prescott CA, Kendler KS. Low extraversion and high neuroticism as indices of genetic and environmental risk for social phobia, agoraphobia, and animal phobia. Am J Psychiatry. 2007;164(11):1714-21.

22. Cox BJ, MacPherson PS, Enns MW, McWilliams LA. Neuroticism and selfcriticism associated with posttraumatic stress disorder in a nationally representative sample. Behav Res Ther. 2004;42(1):105-14.

23. Breslau N, Schultz L. Neuroticism and post-traumatic stress disorder: a prospective investigation. Psychol Med. 2013;43(8):1697-702.

24. Jaksic N, Brajkovic L, Ivezic E, Topic R, Jakovljevic M. The role of personality traits in posttraumatic stress disorder (PTSD). Psychiatr Danub. 2012;24(3):256-66.

25. Engelhard IM, van den Hout MA, Schouten EGW. Neuroticism and low educational level predict the risk of posttraumatic stress disorder in women after miscarriage or stillbirth. Gen Hosp Psychiatry. 2006;28(5):414-7.

26. SFS1974:595: The Swedish Abortion Act [Abortlag 1974:595]. Sveriges riksdag.

27. The National Board of Health and Welfare: Statistics on induced abortions 2014

28. The National Board of Health and Welfare: OFFICIAL STATISTICS OF SWEDEN, Statistics - Health and Medical Care, Induced abortions 2010.

29. Wallin Lundell I, Sundstrom Poromaa I, Frans O, Helstrom L, Hogberg U, Moby L, Nyberg S, Sydsjo G, Georgsson Ohman S, Ostlund I, et al. The prevalence of posttraumatic stress among women requesting induced abortion. Eur J Contracept Reprod Health Care. 2013;18(6):480-8.

30. Wallin Lundell I, Ohman SG, Sundstrom Poromaa I, Hogberg U, Sydsjo G, Skoog Svanberg A. How women perceive abortion care: a study focusing on healthy women and those with mental and posttraumatic stress. Eur J Contracept Reprod Health Care. 2015:1-12.

31. American Psychiatric Association: Diagnostic and statistical manual of mental disorder, 4th edn. (DSM-IV). In. Washington DC: American Psychiatric Association; 1994

32. Breslau N, Lucia VC, Davis GC. Partial PTSD versus full PTSD: an empirical examination of associated impairment. Psychol Med. 2004;34(7):1205-14.

33. Gustavsson JP, Bergman H, Edman G, Ekselius L, IV K, Linder J. Swedish universities scales of personality (SSP): construction, internal consistency and normative data. Acta Psychiatr Scand. 2000;102(3):217-25

34. Schalling D, Asberg M, Edman G, Oreland L. Markers for vulnerability to psychopathology: temperament traits associated with platelet MAO activity. Acta Psychiatr Scand. 1987;76(2):172-82

35. Vohma U, Aluoja A, Vasar V, Shlik J, Maron E. Evaluation of personality traits in panic disorder using Swedish universities scales of personality. J Anxiety Disord. 2010;24(1):141-6.

36. Oberg M, Stenson K, Skalkidou A, Heimer G. Prevalence of intimate partner violence among women seeking termination of pregnancy compared to women seeking contraceptive counseling. Acta Obstet Gynecol Scand. 2014;93(1):45-51.

37. Fisher WA, Singh SS, Shuper PA, Carey M, Otchet F, MacLean-Brine D, Dal Bello D, Gunter J. Characteristics of women undergoing repeat induced abortion. CMAJ. 2005;172(5):637-41.

38. Christiansen DM, Hansen M. Accounting for sex differences in PTSD: a multivariable mediation model. Eur J Psychotraumatol. 2015;6:26068.

39. Engelhard IM, van den Hout MA, Kindt M. The relationship between neuroticism, pre-traumatic stress, and post-traumatic stress: a prospective study. Pers Individ Dif. 2003;35(2):381-8.
40. Hettema JM, Neale MC, Myers JM, Prescott CA, Kendler KS. A populationbased twin study of the relationship between neuroticism and internalizing disorders. Am J Psychiatry. 2006;163(5):857-64.

41. Vinkhuyzen AA, Pedersen NL, Yang J, Lee SH, Magnusson PK, lacono WG, McGue M, Madden PA, Heath AC, Luciano M, et al. Common SNPs explain some of the variation in the personality dimensions of neuroticism and extraversion. Transl Psychiatry. 2012;2:e102.

42. Taft $C$, Creech SK, Kachadourian L. Assessment and treatment of posttraumatic anger and aggression: a review. J Rehabil Res Dev. 2012;49(5):777-88.

43. Afifi TO, Asmundson GJ, Taylor S, Jang KL. The role of genes and environment on trauma exposure and posttraumatic stress disorder symptoms: a review of twin studies. Clin Psychol Rev. 2010;30(1):101-12.

44. Leung TW, Leung WC, Chan PL, Ho PC. A comparison of the prevalence of domestic violence between patients seeking termination of pregnancy and other general gynecology patients. Int J Gynaecol Obstet. 2002;77(1):47-54.

45. Sveen J, Ekselius L, Gerdin B, Willebrand M. A prospective longitudinal study of posttraumatic stress disorder symptom trajectories after burn injury. J Trauma. 2011;71(6):1808-15.

46. Willebrand M, Andersson G, Ekselius L. Prediction of psychological health after an accidental burn. J Trauma. 2004:57(2):367-74

47. Linden M. Posttraumatic embitterment disorder. Psychother Psychosom. 2003;72(4):195-202.

48. Jakupcak M, Conybeare D, Phelps L, Hunt S, Holmes HA, Felker B, Klevens M, McFall ME. Anger, hostility, and aggression among Iraq and Afghanistan war veterans reporting PTSD and subthreshold PTSD. J Trauma Stress. 2007; 20(6):945-54.

49. Diagnostic and statistical manual of mental disorders : DSM-5. Arlington, Va.: American Psychiatric Association; 2013.

50. Taft CT, Vogt DS, Marshall AD, Panuzio J, Niles BL. Aggression among combat veterans: relationships with combat exposure and symptoms of posttraumatic stress disorder, dysphoria, and anxiety. J Trauma Stress. 2007; 20(2):135-45.

51. Allen B, Lauterbach D. Personality characteristics of adult survivors of childhood trauma. J Trauma Stress. 2007;20(4):587-95.

52. Breslau N, Davis GC, Andreski P. Risk factors for PTSD-related traumatic events: a prospective analysis. Am J Psychiatry. 1995;152(4):529-35.

53. Kazdin AE. Research design in clinical psychology. Pearson new international edition: Harlow; 2010.

54. Friedman MJ, Keane TM, Resick PA. Handbook of PTSD : science and practice. New York: Guilford Press; 2007.

\section{Submit your next manuscript to BioMed Central and we will help you at every step:}

- We accept pre-submission inquiries

- Our selector tool helps you to find the most relevant journal

- We provide round the clock customer support

- Convenient online submission

- Thorough peer review

- Inclusion in PubMed and all major indexing services

- Maximum visibility for your research

Submit your manuscript at www.biomedcentral.com/submit 